\title{
A Teenager Diagnosed as Lymphocytic Hypophysitis Associated with Systemic Lupus Erythematosus (SLE)
}

\author{
Jing E${ }^{1}$, Li Cao ${ }^{1}$, Hui Wang ${ }^{1}$, Li Bao ${ }^{1}$, Hong-Yan Luo ${ }^{1}$, Jing $\mathrm{Li}^{2}$ and Ya-Li Zheng ${ }^{{ }^{*}}$ \\ ${ }^{1}$ Deptment of Nephrology in Ningxia People's Hospital, Ningxia, Yinchuan, 750001, China \\ ${ }^{2}$ Department of Pathology in Ningxia People's Hospital, Ningxia, Yinchuan, 750001, China
}

*Corresponding author: Ya-Li Zheng, Department of Nephrology in Ningxia People's Hospital, Ningxia, Yinchuan, 750001, China, Tel: 15825382806; E-mail: antar. 0107@163.com

Received date: April 03, 2014; Accepted date: April 22, 2014; Published date: April 28, 2014

Copyright: ( 2014 Jing E, et al. This is an open-access article distributed under the terms of the Creative Commons Attribution License, which permits unrestricted use, distribution, and reproduction in any medium, provided the original author and source are credited.

\begin{abstract}
A 15-year-old female was admitted to our hospital with intermittent fever, cough and sputum for one week, and diagnosed as pneumonia. Because of no clinic remission with antibiotic and antiviral treatment for one week and following with facial erythema, severe anemia, and neutropenia, appropriate screening laboratory examinations showed severe lower complements (C3, C4) and positives autoantibody such as ANA, ds DNA, Anti-Sm etc, Therefore, SLE was diagnosed with muti-organs involved including lungs, blood, liver, kidney, medical peritonitis, and central nervous system presented as irritable and moody. Because the patient complained of dizziness, fatigue, anorexia, hands trembling and showed a very indifferent mood, endocrinological tests were took. The results revealed very low levels of sex hormones, thyroid hormones and serum cortisol, and manifested as hypopituitarism. Magnetic resonance imaging (MRI) of pituitary region demonstrated a mild enlargement of the pituitary stalk. SLE associated with Lymphocytic hypophysitis (LYH) was suspected. And the clinical symptoms and laboratory tests were ameliorated after glucocorticoid treatment (involve twice methylprednisolone (MPIV) pulse therapy and oral 40 $\mathrm{mg} / \mathrm{d}$ of MPIV) combined with cyclophosphamide therapy. Although, LYH associated with SLE have been reported, a 15-year teenager, as seen in this case, is a rare first presentation of SLE.
\end{abstract}

Keywords: Systemic Lupus Erythematosus (SLE); Lymphocytic hypophysitis (LYH); Hypopituitarism; Glucocorticoid

\section{Introduction}

SLE is a chronic multisystem autoimmune inflammatory disorder characterized by a large range of variable clinical, serological manifestations, and a relapsing-remitting course $[1,2]$. The association of SLE and LYH is rare. To our knowledge, only four cases of LYH involving three Lymphocytic adenohypophysitis (LAH) and one lymphocytic infundibuloneurohypophysitis (LINH) associated with SLE were reported [3-6]. LYH which can be classified as LAH and LINH is an organ-specific autoimmune disease in which the pituitary gland is enlarged secondary to inflammatory infiltration and destruction of pituitary gland [7]. But LYH precise incidence, etiologies and the mechanisms are not well known in contrast with other autoimmune diseases. It affects females far more than males [8]. Clinical manifestations of LYH mainly include four major categories of symptoms like mass oppression, pituitary dysfunction, hyperprolactinemia and neurohypophysis involvement. Herein, we report the first youngest case that was recently diagnosed as LYH related to SLE and discuss the therapies especially methylprednisolone (MPIV) pulse treatment combined with cyclophosphamide in such disease.

\section{Case Report}

A 15-year-old female who had no special medical history and any incentives suffered from fever, cough and sputum a week ago, and was diagnosed as pneumonia. There was no remission after three days treatment with cephalosporins, ganciclovir and three days treatment with Teicoplanin in a local clinic. The temperature kept to fluctuate in the $37-39^{\circ} \mathrm{C}$. Consequently, a severe facial erythema was appeared and companied by fatigue, dizziness and anorexia. Then she was presented to our hospital on June 21, 2012.

The results of physical examination including blood pressure, heart rate and respiration rate were normal. The body temperature was 37.9. A butterfly erythema can be seen on bilateral buccal. Visual field examination was normal. The breath sounds of lungs were coarse. There were no wet and dry rales in lungs. The remainder of the examination was unremarkable.

On Laboratory examination, hematological exam, Blood chemistry and urine analysis were shown in Tables 1-3. Chest X-ray showed patch clouding opacity in double lower lobes and bilateral hydrothorax. Immunological examination showed that anti-nuclear antibody, anti-double stranded DNA antibody, anti-Sm antibody, anti-nRNP/Sm, anti-SSA, anti-nucleosome antibody and antiribosomal $\mathrm{P}$ antibodies were all positive. Serum complement 3 (C3 $0.17 \mathrm{~g} / \mathrm{l})$ and complement $4(\mathrm{C} 42.83 \mathrm{~g} / \mathrm{l})$ were very low. Based on clinical symptoms and laboratory tests, the SLE was diagnosed. Because the patient always complained of general malaise such as dizziness, fatigue, and anorexia, combined with her very indifferent mood and hands trembling, relevant examinations such as sex hormones, thyroid hormones and serum cortisol were tested. The results showed that estradiol (E2), follicle stimulating hormone (FSH), progesterone (PRGE), prolactin (PRL), luteotrophic hormone(LH) and testosterone (TSTO) were all very low: $11.8 \mathrm{pg} / \mathrm{ml}, 1.2 \mathrm{mIU} / \mathrm{ml}$, $0.03 \mathrm{ng} / \mathrm{dl}, 4.9 \mathrm{ng} / \mathrm{ml}, 0.3 \mathrm{mIU} / \mathrm{ml}$ and $0.01 \mathrm{ng} / \mathrm{dl}$, respectively; free T3 (FT3), free T4 (FT4) and thyrotrophic-stimulating hormone (TSH) were as low as $1.1 \mathrm{pg} / \mathrm{ml}, 0.66 \mathrm{ng} / \mathrm{dl}$, and $0.092 \mathrm{IU} / \mathrm{ml}$ respectively. 
Citation: Jing E, Li Cao, Hui Wang, Li Bao, Hong-Yan Luo, et al. (2014) A Teenager Diagnosed as Lymphocytic Hypophysitis Associated with Systemic Lupus Erythematosus (SLE). J Blood Disorders Transf 5: 221. doi:10.4172/2155-9864.1000221

Page 2 of 5

Thyroid antibodies were negative. Serum cortisol was also very low: $8.7 \mathrm{ug} / \mathrm{ml}$ at $8 \mathrm{am}$ and $1.2 \mathrm{ug} / \mathrm{ml}$ at $4 \mathrm{pm}$. All hormones examinations demonstrated that she had hypopituitarism.

\begin{tabular}{|l|l|l|l|l|l|l|l|l|}
\hline $\begin{array}{l}\text { Blood } \\
\text { chemistry }\end{array}$ & $\begin{array}{l}\text { ALT } \\
\text { (U/L) }\end{array}$ & $\begin{array}{l}\text { AST } \\
\text { (U/L) }\end{array}$ & $\begin{array}{l}\text { TP } \\
(\mathbf{g} / \mathbf{d l})\end{array}$ & $\begin{array}{l}\text { ALB } \\
\text { (g/dl) })\end{array}$ & $\begin{array}{l}\mathbf{C r} \\
(\mathbf{u m o l} / \mathbf{l})\end{array}$ & $\begin{array}{l}\text { BUN } \\
(\mathbf{m m o l} / \mathbf{l})\end{array}$ & $\begin{array}{l}\text { C3 } \\
\mathbf{( g / l )}\end{array}$ & $\begin{array}{l}\mathbf{C 4} \\
\mathbf{( g / l )}\end{array}$ \\
\hline At onset & 168 & 283 & 0.55 & 0.3 & 59 & 6.85 & 0.12 & 4.49 \\
\hline $\begin{array}{l}\text { After the 1st } \\
\text { MPIV Pulse }\end{array}$ & 114 & 32 & 0.52 & 0.31 & 42 & 5.2 & 0.19 & 3.83 \\
\hline $\begin{array}{l}\text { After the 2rd } \\
\text { MPIV Pulse }\end{array}$ & 9 & 11 & 0.47 & 0.19 & 44 & 5.13 & 0.57 & 15.9 \\
\hline
\end{tabular}

Table 1: Hematological exam changes in patient before and after treatment, WBC: White Blood Cell; Gran: Eosinophilic Granulocyte; Lymph: Lymphocyte; Eos: Monocyte; BASO: Basophilic Granulocyte; Hg: Hemoglobin; PLT: Platelet; Hct: Hematocrit Value.

\begin{tabular}{|l|l|l|l|l|l|l|l|l|}
\hline $\begin{array}{l}\text { Blood } \\
\text { chemistry }\end{array}$ & $\begin{array}{l}\text { ALT } \\
\text { (U/L) }\end{array}$ & $\begin{array}{l}\text { AST } \\
\text { (U/L) }\end{array}$ & $\begin{array}{l}\text { TP } \\
\text { (g/dl) }\end{array}$ & $\begin{array}{l}\text { ALB } \\
\text { (g/dl) })\end{array}$ & $\begin{array}{l}\text { Cr } \\
\text { (umol/l) })\end{array}$ & $\begin{array}{l}\text { BUN } \\
\text { (mmol/l) }\end{array}$ & $\begin{array}{l}\text { C3 } \\
\text { (g/l) }\end{array}$ & $\begin{array}{l}\text { C4 } \\
\text { (g/l) }\end{array}$ \\
\hline At onset & 168 & 283 & 0.55 & 0.3 & 59 & 6.85 & 0.12 & 4.49 \\
\hline $\begin{array}{l}\text { After the } \\
\text { st MPIV } \\
\text { Pulse }\end{array}$ & 114 & 32 & 0.52 & 0.31 & 42 & 5.2 & 0.19 & 3.83 \\
\hline $\begin{array}{l}\text { After the } \\
\text { 2rd MPIV } \\
\text { Pulse }\end{array}$ & 9 & 11 & 0.47 & 0.19 & 44 & 5.13 & 0.57 & 15.9 \\
\hline
\end{tabular}

Table 2: Blood chemistry changes in patient at onset and after treatment, ALT: Alanine Aminotransferase; AST: Aspartate Aminotransferase; TP: Total Protein; ALB: Albumin; Cr: Creatinine; BUN: Urea Nitrogen; C3: Complement 3; C4: Complement 4

\begin{tabular}{|l|l|l|l|l|}
\hline Urine test & Pro & BLD & WBC/HPF & RBC/HPF \\
\hline At onset & $(1+)$ & $(+-)$ & 1.5 & 8.2 \\
\hline After the first MPIV Pulse therapy & $(3+)$ & $(3+)$ & 38.4 & 393.6 \\
\hline After the second MPIV Pulse therapy & $(3+)$ & $(3+)$ & 12.5 & 156.8 \\
\hline
\end{tabular}

Table 3: Urine analysis changes in patient before and after treatment, Pro: protein uria; BLD: urine occult blood

MRI of pituitary region demonstrated a mild enlargement of the pituitary stalk (Figure 1). LYH was suspected on the strength of clinical symptoms, endocrine function, as well as pituitary MRI. The patient refused pituitary biopsy, and selected the conservative treatments. Considering the patient combined with multiple organs damage, MPIV pulse therapy (MPIV $500 \mathrm{mg} / \mathrm{d}$, i.v.d x 3days) were adopted and then followed by oral $40 \mathrm{mg} / \mathrm{d}$ of MPIV, meanwhile cyclophosphamide (CTX, $200 \mathrm{mg}$, i.v.d) was given every other day. There were no symptoms suggestive of glucocorticoid deficiency during the treatment. Along with the progress of treatment, the trend graph of endocrine hormone was shown in Figure 2. Because the patient appeared more and more proteinuria, the renal biopsy was performed. And the renal pathological diagnosis was diffuse glomerulonephritis [IV-G(A)] (Figure 3), combined with accelerated erythrocyte sedimentation rate and high level of serum C-reactive protein (CRP), the second MPIV pulse therapy (MPIV $500 \mathrm{mg} / \mathrm{d}$, i.v.d $\mathrm{x} 3$ days) was given. The variation of $24 \mathrm{~h}$ urine protein can be seen in Figure 4. And six weeks later, the clinical symptoms and hypopituitarism were ameliorated obviously. The regression of the pituitary mass was also noticed after a replacement dose of MPIV treatment, which indirectly confirms our initial diagnosis of LYH (Figure 1, diagram $\mathrm{C}$ and $\mathrm{D}$ ). But now the patient suffers from menstrual disturbances and her PRGE continues to decrease. It may relate to SLE which lead ovarian function dysfunction. Meanwhile the cortisol continued below normal level that may associated with SLE and LYH.

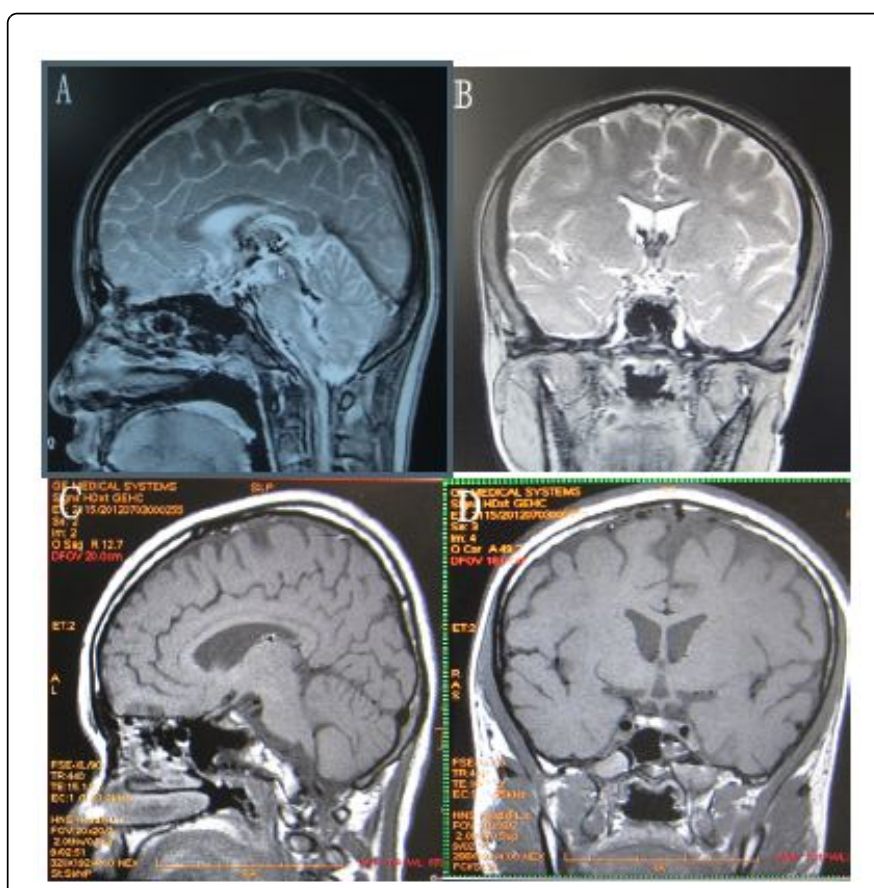

Figure 1: Magnetic resonance imaging of pituitary region. (Magnetic resonance imaging of pituitary regions $\mathrm{A}$ and $\mathrm{B}$ show the image before glucocorticoid treatment, $\mathrm{C}$ and $\mathrm{D}$ show the image after glucocorticoid treatment).

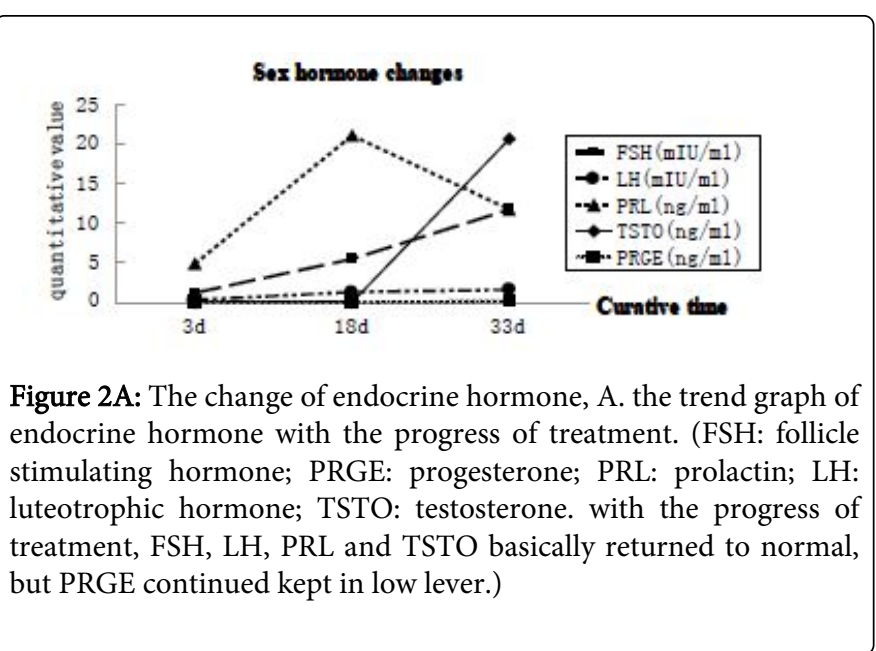


Citation: Jing E, Li Cao, Hui Wang, Li Bao, Hong-Yan Luo, et al. (2014) A Teenager Diagnosed as Lymphocytic Hypophysitis Associated with Systemic Lupus Erythematosus (SLE). J Blood Disorders Transf 5: 221. doi:10.4172/2155-9864.1000221

Page 3 of 5

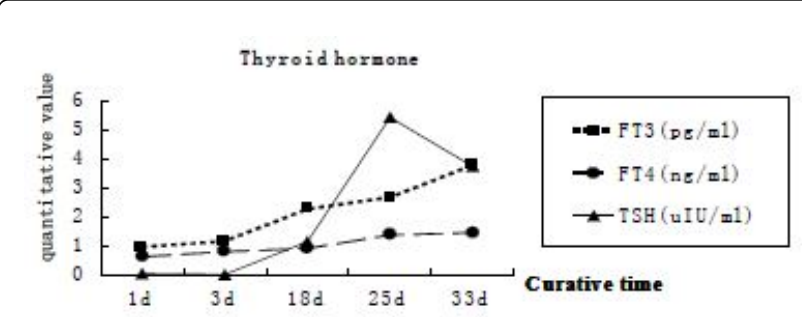

Figure 2B: The trend graph of thyroid hormone with the progress of treatment, (FT3: free T3; FT4: free T4; TSH: thyrotropicstimulating hormone. With the treatment of methylprednisolone combined with cyclophosphamide, the thyroid hormone gradually increased to normal.)

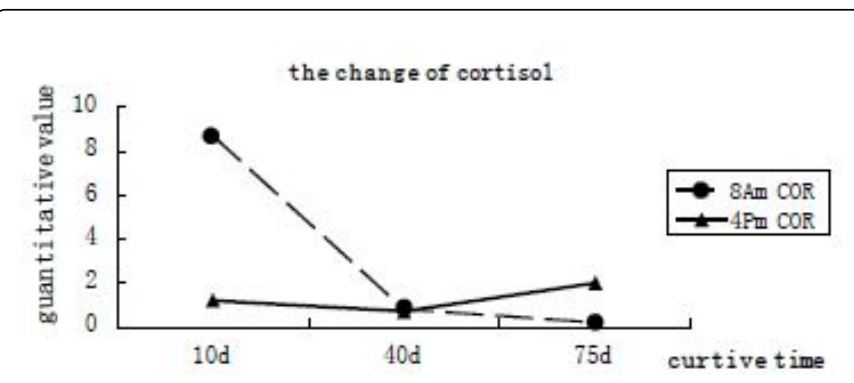

Figure 2C: The trend graph of serum cortisol with the progress of treatment (COR: serum cortisol. The cortisol maintained in low lever at before and after treatment which may related to LYH)

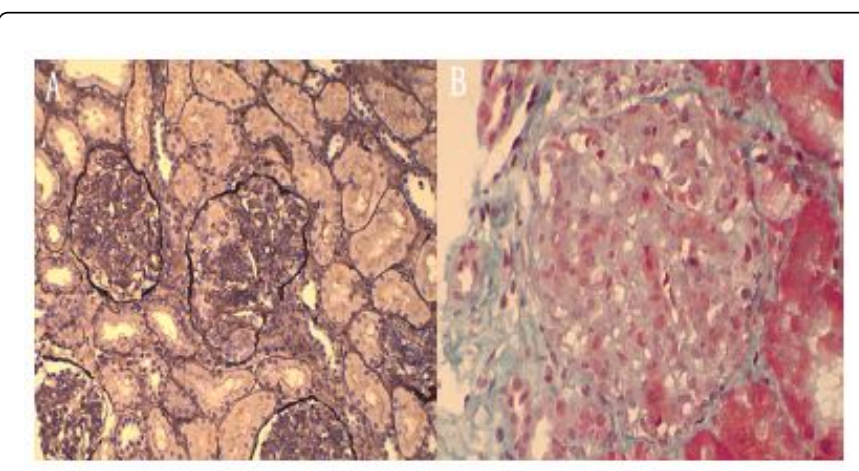

Figure 3: Pathology of kidney biopsy, (The pathology of kidney biopsy showed diffuse glomerulonephritis.)

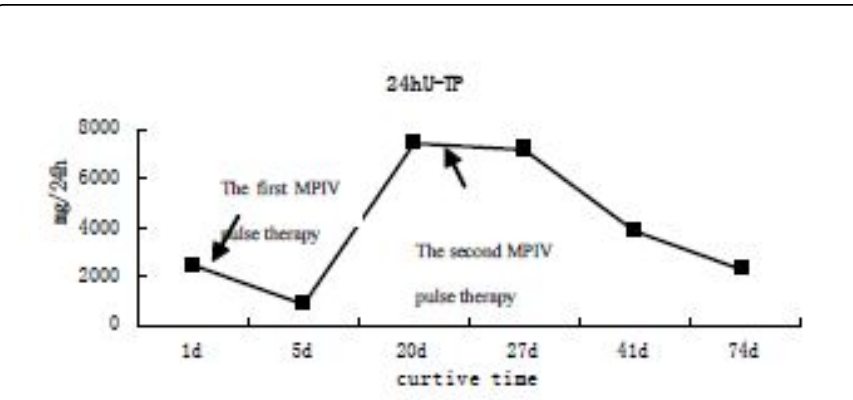

Figure 4: With the progress of treatment, the tread graph of $24 \mathrm{~h}$ urine protein, (the variation of $24 \mathrm{~h}$ urine protein with the glucocorticoid treatment.)

\section{Discussion}

SLE is an autoimmune inflammatory disease characterized by a large range of variable clinical and serological manifestation, usually requiring hospitalization and glucocorticoids combined with immunosuppressive therapy. Patients with SLE generally presented endocrine symptoms which mainly manifest as hyperprolactinemia, hypothyroidism or hyperthyroidism [9]. The secretion of sex hormones such as LH and FSH also increase, but in contrary to TSTO in the activity period of SLE. Its mechanism was related to the dysfunction of ovary and cytokines produced by the haemopoietic tissues which exert regulatory influence on the hypothalamic-pituitary axis [10]. However, the patient in our case presented panhypopituitarism which not just simply related to SLE activity. Based on the clinical symptoms, endocrine function and MRI finding, the diagnosis of LYH was considered.

LYH is an organ-specific autoimmune disease of the pituitary gland which may present with clinical symptoms including headaches, visual symptoms, central diabetes insipidus (DI) and signs of hypopituitarism. The first case was described in 1962 in a female after parturition [11]. LYH frequently coexists with other autoimmune disorders, most common association with chronic thyroiditis, Graves' disease, and DI, some cases like pernicious anemia, atrophic gastritis, hypoparathyroidism, and primary biliary cirrhosis [12]. SLE was less frequently reported association with LYH. To our knowledge, only four cases of LYH involving three LAH and one LINH associated with SLE were reported. LYH is considered a syndrome distinguishing disorders between the anterior pituitary (LAH) and the posterior pituitary (LINH).The characteristic of LAH is inflammation, swelling and destruction of the anterior pituitary which clinical manifestation is fatigue, anorexia, night sweats, drowsiness and hypopituitarism. The features of LINH are central DI. If the suprasellar region and optic chiasm are involved by enlargement of pituitary, symptoms of headache and abnormal visual field will present. Some case puts forward the definition of lymphocytic panhypophysitis which leads to DI and hypopituitarism when both LAH and LINH are existed [13]. In our case, the LYH associated with SLE which involved multisystem manifested hypogonadotropic hypogondism, hypothyroidism, and hypoadrenalism called as hypopituitarism. According to the symptoms such as fatigue, anorexia, apathetic expression, hypopituitaryism, and MRI image, this case considered as LAH, and subsequent therapeutic effect also confirmed the initial diagnosis of LAH. Although there were three LAH of LYH associated with SLE has reported, a 15 years old 
teenager, as seen in our case, is rare first case of LYH associated with SLE. In addition to the diagnosis of LYH associated with SLE, LYH associated with viral, bacterial infection and drugs(antibiotics or antiviral agents) could also be diagnosed and confirmed by the response to steroid treatment. To our knowledge, some secondary LYH were caused by defined bacterial, fungal and viral agents, including HIV [14]. One case had exactly reported rubella virus can induce LYH [15]. Besides, LYH also can be caused by drugs such as ipilimumap [16]. Unfortunately, some examination like viral and bacterial exam, lung and pituitary biopsy were not done in our case. But a possible viral or bacterial illness as the unifying aetiological cause cannot be ruled out in this case.

Up to now, the prevalence of LYH is still infrequent, and exact incidence remains unclear. The gold criterion of diagnosis for LYH is pituitary biopsy which can observe massive infiltration of lymphocytes and plasma cells in the pituitary gland. As an invasive test, however, it was usually objected by patients if they do not have symptoms of mass oppression. Just like patient in our case, she only manifested as hypopituitarism and didn't suffer from headache, visual disturbance and DI. Therefore, she refused to do the pituitary biopsy, and selected conservative treatments. Most cases make diagnosis based on clinical symptoms, endocrine tests, autoimmune antibody and MRI of pituitary. The characteristically manifestation of LYH in MRI is homogeneous contrast enhancement of the pituitary gland appearing as triangular shaped, but it is not specific for LYH. In some cases, the stalk only can be seen thickened [17], in rare cases an empty sella can represent an unusual feature of LYH at MRI [18]. The treatment of LYH remains controversial. According to the different expressions of LYH require different therapeutic methods. Glucocorticoids as conservative treatments can ameliorate clinical symptoms in according to reducing lymphocytic infiltration of the pituitary. Now whether glucocorticoid pulse therapy or low dose glucocorticoid therapy are both demonstrated beneficial. Nishioka et al. proposed that glucocorticoid should be attempted in the early stage of the disease [19]. Hashimoto et al. reported that patients with LAH treated with glucocorticoids showed obviously reduction of pituitary mass [20]. In addition, adopting high dose MPIV pulse therapies for 2 weeks can observe improvement in recovering hormonal abnormality in some cases [21]. Meanwhile, some cases adapt glucocorticoid combined with immunosuppressive therapy. Guo-Qing Yang et al. demonstrated that glucocorticoids plus azathioprine is useful for treating recurrent LYH [22]. If the patients have brain compression and visual disturbance, surgery should be considered. Except glucocorticoid and surgery treatments, it has been reported that pituitary stereotactic radiotherapy is a useful approach for patients who unresponsive to surgery or glucocorticoids [23]. In our case, we used twice a large dose MPIV pulse therapy on earlier stage of disease, and oral $40 \mathrm{mg} / \mathrm{d}$ of MPIV combined with cyclophosphamide therapy. We observed the improvement of clinal symptoms, reduction of pituitary mass, and recovering hormonal abnormalities, except the serum cortisol and PRGE continue around low level which may relate to anterior hypophysitis and SLE that lead to ovary dysfunction.

\section{Conclusion}

It is important for the patients who diagnosed as SLE to take endocrine hormones examinations, and if results were abnormal, a MRI of pituitary in suspicion of pituitary gland disease should be done as early as possible to discover whether LYH is accompanied,
Admission of glucocorticoid in early stage may be benefit to outcome of disease.

\section{References}

1. Hochberg MC (1997) Updating the American College of Rheumatology revised criteria for the classification of systemic lupus erythematosus. Arthritis Rheum 40: 1725.

2. Symmons DP, Coppock JS, Bacon PA, Bresnihan B, Isenberg DA, et al. (1988) Development and assessment of a computerized index of clinical disease activity in systemic lupus erythematosus. Members of the British Isles Lupus Assessment Group (BILAG). Q J Med 69: 927-937.

3. Kawano T, Kobayashi S, Ebizuka T, Tanaka M, Ikeda M, et al. (1994) [Hypopituitarism associated with empty sella after steroid pulse therapy in a patient with SLE]. Ryumachi 34: 54-58.

4. Katano H, Umemura A, Kamiya K, Kanai H, Yamada K (1998) Visual disturbance by lymphocytic hypophysitis in a non-pregnant woman with systemic lupus erythematosus. Lupus 7: 554-556.

5. Takao T, Asaba K, Tanaka H, Matsumoto R, Nanamiya W, et al. (2000) A case of lymphocytic infundibuloneurohypophysitis showing diabetes insipidus followed by anterior hypopituitarism associated with thrombasthenia. Endocr J 47: 285-291.

6. Kozo Hashimoto, Koichi Asaba, Kanae Tamura, Toshihiro Takao, Nakamura T, et al. (2002) A case of lymphocytic hypophysitis associated with systemic lupus erythematousus. Endocr J 49(6): 605-610.

7. Jenkins PJ, Chew SL, Lowe DG, Afshart F, Charlesworth M, et al. (1995) Lymphocytic hypophysitis: unusual features of a rare disorder. Clin Endocrinol (Oxf) 42: 529-534.

8. Feigenbaum SL, Martin MC, Wilson CB, Jaffe RB (1991) Lymphocytic adenohypophysitis: a pituitary mass lesion occurring in pregnancy. Proposal for medical treatment. Am J Obstet Gynecol 164: 1549-1555.

9. Verthelyi D, Klinman DM (2000) Sex hormone levels correlate with the activity of cytokine-secreting cells in vivo. Immunology 100: 384-390.

10. Chikanza IC, Grossman AB (2000) Reciprocal interactions between the neuroendocrine and immune systems during inflammation. Rheum Dis Clin North Am 26: 693-711.

11. GOUDIE RB, PINKERTON PH (1962) Anterior hypophysitis and Hashimoto's disease in a young woman. J Pathol Bacteriol 83: 584-585.

12. Caturegli P, Newschaffer C, Olivi A, Pomper MG, Burger PC, et al. (2005) Autoimmune hypophysitis. Endocr Rev 26: 599-614.

13. Cheung CC, Ezzat S, Smyth HS, Asa SL (2001) The spectrum and significance of primary hypophysitis. J Clin Endocrinol Metab 86: 1048-1053.

14. Sano T, Kovacs K, Scheithauer BW, Rosenblum MK, Petito CK, et al. (1989) Pituitary pathology in acquired immunodeficiency syndrome. Arch Pathol Lab Med 113: 1066-1070.

15. Yoon JW, Choi DS, Liang HC, Baek HS, Ko IY, et al. (1992) Induction of an organ-specific autoimmune disease, lymphocytic hypophysitis, in hamsters by recombinant rubella virus glycoprotein and prevention of disease by neonatal thymectomy. J Virol 66: 1210-1214.

16. Holm Thomsen H (2012) [Lymphocytic hypophysitis due to ipilimumap therapy]. Ugeskr Laeger 174: 1829-1830.

17. Ahmadi J, Meyers GS, Segall HD, Sharma OP, Hinton DR (1995) Lymphocytic adenohypophysitis: contrast-enhanced MR imaging in five cases. Radiology 195: 30-34.

18. Nishiyama S, Takano T, Hidaka Y, Takada K, Iwatani Y, et al. (1993) A case of postpartum hypopituitarism associated with empty sella: possible relation to postpartum autoimmune hypophysitis. Endocr J 40: 431-438.

19. Nishioka H, Ito H, Fukushima C (1997) Recurrent lymphocytic hypophysitis: case report. Neurosurgery 41: 684-686.

20. Hashimoto K Asaba K, Tamura K, Takao T, Nakamura T (2002) A case of lymphocytic infundibuloneurohypophysitis associated with systemic lupus erythematosus. Endocr J 49: 605-610.

21. Kristof RA, Van Roost D, Klingmüller D, Springer W, Schramm J (1999) Lymphocytic hypophysitis: non-invasive diagnosis and treatment by high 
Citation: Jing E, Li Cao, Hui Wang, Li Bao, Hong-Yan Luo, et al. (2014) A Teenager Diagnosed as Lymphocytic Hypophysitis Associated with Systemic Lupus Erythematosus (SLE). J Blood Disorders Transf 5: 221. doi:10.4172/2155-9864.1000221

Page 5 of 5

dose methylprednisolone pulse therapy? J Neurol Neurosurg Psychiatry 67: 398-402.

22. Yang GQ, Lu ZH, Gu WJ, Du J, Guo QH, et al. (2011) Recurrent autoimmune hypophysitis successfully treated with glucocorticoids plus azathioprine: a report of three cases. Endocr J 58: 675-683.
23. Selch MT, DeSalles AA, Kelly DF, Frighetto L, Vinters HV, et al. (2003) Stereotactic radiotherapy for the treatment of lymphocytic hypophysitis. Report of two cases. J Neurosurg 99: 591-596. 